\title{
Standards of Practice in Acute Ischemic Stroke Intervention International Recommendations
}

\author{
Laurent Pierot, Mahesh Jarayaman, Istvan Szikora, Joshua Hirsch, Blaise Baxter,
} Shigeru Miyachi, Jeyaledchumy Mahadevan, Winston Chong, Peter J. Mitchell, Alan Coulthard, Howard A. Rowley, Pina C. Sanelli, Donatella Tampieri, Patrick Brouwer, Jens Fiehler, Naci Kocer, Pedro Vilela, Alex Rovira, Urs Fischer, Valeria Caso, Bart van der Wort, Nobuyuki Sakai, Yuji Matsumaru, Shin-ichi Yoshimura, Luisa Biscoito, Manuel Pumar, Orlando Diaz, Justin Fraser, Italo Lifante, David S. Liebeskind, Raul G. Nogueira, Werner Hacke, Michael Brainin, Bernard Yan, Michael Soderman, Allan Taylor, Sirintara Pongpech, Karel Terbrugge; on behalf of the Asian-Australian Federation of Interventional and Therapeutic Neuroradiology (AAFITN), the Australian-New Zealand Society of Neuroradiology (ANZSNR), the American Society of Neuroradiology (ASNR), the Canadian Society of Neuroradiology (CSNR), the European Society of Minimally Invasive Neurological Therapy (ESMINT), the European Society of

Neuroradiology (ESNR), the European Stroke Organization (ESO), the Japanese Society for Neuro Endovascular Therapy (JSNET), the Society Ibero-Latino Americana of Diagnostic and Therapeutic Neuroradiology (SILAN), the Society of Neurointerventional Surgery (SNIS), the Society of Vascular and Interventional Neurology (SVIN), the World Stroke Organization (WSO), the World Federation of Interventional and Therapeutic Neuroradiology (WFITN).

\begin{abstract}
After five positive randomized controlled trials showed benefit of mechanical thrombectomy in the management of acute ischemic stroke with emergent large-vessel occlusion, a multi-society meeting was organized during the 17 th Congress of the World Federation of Interventional and Therapeutic Neuroradiology in October 2017 in Budapest, Hungary. This multi-society meeting was dedicated to establish standards of practice in acute ischemic stroke intervention aiming for a consensus on the minimum requirements for centers providing such treatment. In an ideal situation, all patients would be treated at a center offering a full spectrum of neuroendovascular care (a level 1 center). However, for geographical reasons, some patients are unable to reach such a center in a
\end{abstract}

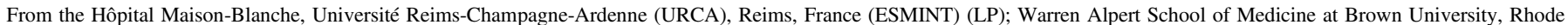

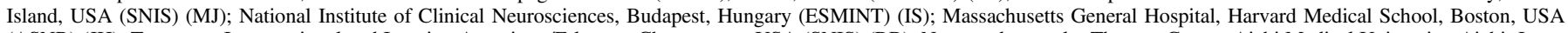

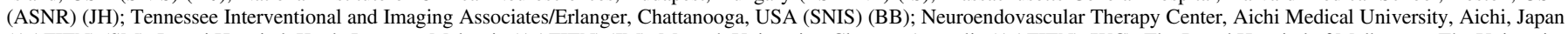

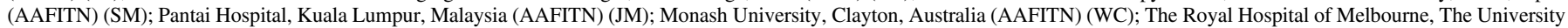

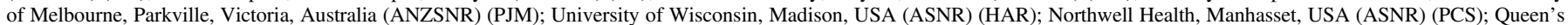

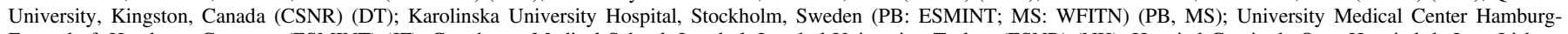

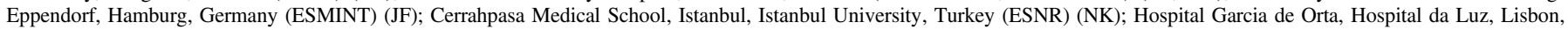

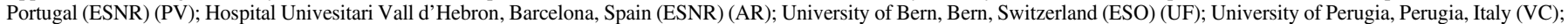

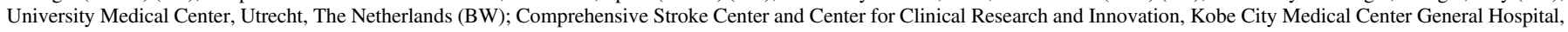

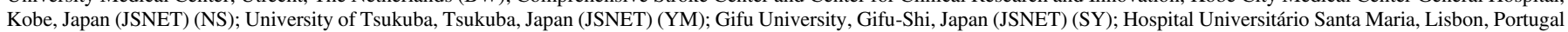

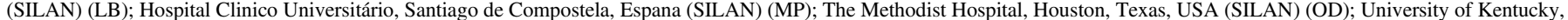

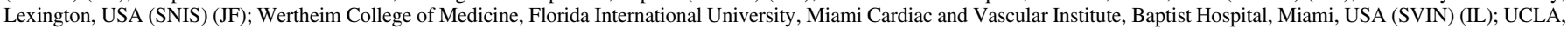

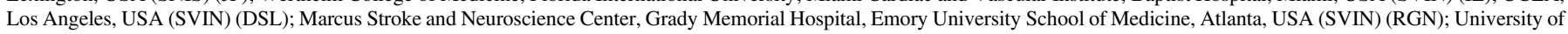

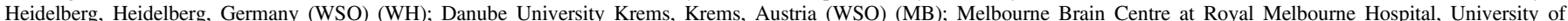

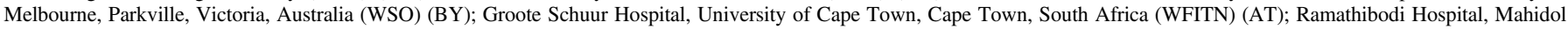

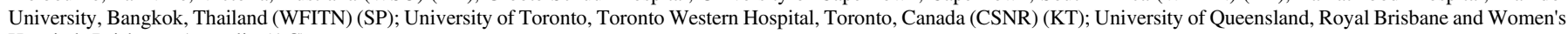
Hospital, Brisbane, Australia (AC).

Received November 23, 2018. Final Revisions Submitted November 30, 2018. Date of Acceptance November $30,2018$.

Correspondence to: Karel Terbrugge, Toronto Western Hospital, 399 Bathurst Street, Toronto M5T 2S8, Canada. Email: karel.terbrugge@uhn.ca 
reasonable period of time. With this in mind, the group paid special attention to define recommendations on the prerequisites of organizing stroke centers providing medical thrombectomy for acute ischemic stroke, but not for other neurovascular diseases (level 2 centers). Finally, some centers will have a stroke unit and offer intravenous thrombolysis, but not any endovascular stroke therapy (level 3 centers). Together, these level 1,2, and 3 centers form a complete stroke system of care. The multi-society group provides recommendations and a framework for the development of medical thrombectomy services worldwide.

RÉSUMÉ : Les normes de pratique recommandées à l'échelle internationale lors d'interventions consécutives à un accident ischémique cérébral aigu. En octobre 2017, à Budapest, une rencontre pluridisciplinaire de spécialistes s'est organisée dans le cadre du $17^{\mathrm{e}}$ congrès de la World Federation of Interventional and Therapeutic Neuroradiology. Cette rencontre portait sur l'établissement de normes relatives aux interventions consécutives à des accidents ischémiques aigus. Elle a eu lieu, précisons-le, après que cinq essais randomisés contrôlés (ERC) ont montré les avantages de la thrombectomie mécanique dans la prise en charge de patients victimes d'un accident ischémique cérébral aigu montrant des signes naissants d'occlusion des plus gros vaisseaux sanguins. Les normes dont il a été alors question visaient aussi à atteindre un consensus quant aux exigences minimales auxquelles devaient se conformer les établissements de santé offrant la thrombectomie mécanique. Dans l'idéal, tous les patients devraient être traités dans un établissement offrant un éventail complet de soins neuro-endovasculaires (de niveau 1). Toutefois, en raison de l'éloignement géographique, quelques patients demeurent incapables de se rendre dans un tel établissement dans des délais raisonnables. Dans cette optique, le groupe réuni à Budapest a défini de façon particulière des recommandations définissant les aspects permettant aux autres établissements (de niveau 2) d'organiser en amont des soins en thrombectomie destinés à des patients victimes d'accidents ischémiques cérébraux aigus mais pas d'autres maladies neurovasculaires. Enfin, d'autres établissements (de niveau 3) pourront compter sur une unité de traitement des AVC, notamment au moyen de la thrombolyse intraveineuse; toutefois, ils ne pourront offrir aucune autre thérapie endovasculaire. Réunis, l'ensemble de ces établissements de niveaux 1, 2 et 3 constitue un réseau complet de soins destinés aux patients victimes d'un AVC. Le groupe multidisciplinaire réuni lors de cette rencontre a ainsi élaboré des recommandations et un cadre de référence visant le développement de la thrombectomie dans le monde entier.

Keywords: Stroke, Mechanical thrombectomy, Endovascular

doi:10.1017/cjn.2019.1

Can J Neurol Sci. 2019; 46: 269-274

\section{Preamble}

After the five positive RCTs showing the benefit of mechanical thrombectomy (MT) in the management of acute ischemic stroke (AIS) with emergent large-vessel occlusion (ELVO), a multi-society meeting was organized during the 16th Congress of the World Federation of Interventional and Therapeutic Neuroradiology (WFITN) in October 2015 in Gold Coast (Australia). This meeting was dedicated to the training of physicians performing MT, and recommendations were published thereafter in multiple scientific journals. ${ }^{1}$

The same group of scientific societies decided to organize a similar meeting during the $17^{\text {th }}$ WFITN Congress in October 2017 in Budapest (Hungary). This multi-society meeting was dedicated to standards of practice in acute ischemic stroke intervention (AISI) aiming for a consensus on the minimum requirements for centers providing such treatment.

In an ideal situation, all patients would be treated at a center offering a full spectrum of neuroendovascular care (a level 1 center). However, for geographical reasons, some patients are unable to reach such a center in a reasonable period of time. With this in mind, the group paid special attention to define recommendations on the prerequisites of organizing stroke centers providing MT for AIS, but not for other neurovascular diseases (a level 2 center). Finally, some centers will have a stroke unit and offer intravenous thrombolysis, but not any endovascular stroke therapy (a level 3 center). Together, these level 1, 2, and 3 centers form a complete stroke system of care. The requirements for these centers are summarized in Table 1.

Due to the relatively short time elapsed since the evidence in favor of MT has been published, some organizational aspects still require scientific validation. However, considering the extremely fast growth of such activities around the world, the multi-society group considered it timely and rational to set up recommendations and a framework for the development of MT services in all parts of the world. The requirements included in this document are proposed to help countries and centers to properly implement MT.

\section{Composition of the Consensus Group}

This working group is composed of delegates from the following societies: AAFITN, ANZSNR, ASNR, CSNR, ESMINT, ESNR, ESO, JSNET, SILAN, SNIS, SVIN, WSO, WFITN.

\section{Abbreviations \\ AIS: acute ischemic stroke \\ AISI: acute ischemic stroke intervention \\ MT: mechanical thrombectomy \\ ELVO: emergent large-vessel occlusion}

\section{Definitions}

Neuroendovascular procedures: Minimally invasive, imageguided procedures to treat diseases of the brain and spinal cord. These would include embolization for treatment of intracranial aneurysms, arteriovenous malformations, tumors, and revascularization techniques such as angioplasty and stenting for atherosclerotic disease.

AISI involves percutaneous endovascular procedures to treat ischemic stroke in adults and children, and may involve thrombectomy, aspiration, percutaneous transluminal angioplasty (PTA), and stent implantation as well as superselective drug infusion.

Stroke unit: A dedicated, geographically defined area or ward in a hospital, where stroke patients are admitted and cared for by a multi-professional team (medical, nursing, and therapy staff) who 
Table 1: General summary of capabilities of level 1, 2, and 3 centers

\begin{tabular}{|c|c|c|c|}
\hline & Level 1 center & Level 2 center & Level 3 center \\
\hline $\begin{array}{l}\text { Offers a full spectrum of neuroendovascular } \\
\text { therapy (including treatment of aneurysm, } \\
\text { AVM, AVF, etc.) }\end{array}$ & Yes & No & No \\
\hline Offers endovascular stroke therapy & Yes & Yes & No \\
\hline Offers IV tPA & Yes & Yes & Yes \\
\hline Minimum number of stroke patients per year & 250 & 100 & 50 \\
\hline Minimum thrombectomy volume per year & 50 & 50 & N/A \\
\hline Dedicated neuro-ICU & Yes & Optional & Not needed \\
\hline Dedicated stroke unit & Yes & Yes & Yes \\
\hline Open neurosurgical services on site & Yes & Optional & Not needed \\
\hline Geographic restriction? & No & $\begin{array}{l}\text { Yes (should be more than } 2 \mathrm{~h} \text { transport time } \\
\text { from a level } 1 \text { center) }\end{array}$ & No \\
\hline Inter-facility transfers & $\begin{array}{l}\text { Receives cases from } \\
\text { level } 1 \text { and } 2 \text { centers }\end{array}$ & $\begin{array}{l}\text { Will transfer some cases to a level } 1 \text { center. Will occasionally } \\
\text { receive transfers from level } 3 \text { centers if no level } 1 \text { center is } \\
\text { available within } 2 \mathrm{~h} \text { from the level } 3 \text { center }\end{array}$ & $\begin{array}{l}\text { Has standardized transfer processes in } \\
\text { place with a level } 1 \text { center (preferable), } \\
\text { or a level } 2 \text { center }\end{array}$ \\
\hline
\end{tabular}

have specialist knowledge, training, and skills in stroke care with well-defined individual tasks, regular interaction with other disciplines, and stroke leadership. This team shall coordinate stroke care through regular (weekly) multi-professional meetings (http:// stroke.ahajournals.org/content/44/3/828\#T1).

Stroke center: A hospital infrastructure and related processes of care that provide the full pathway of stroke unit care. A stroke center is the coordinating body of the entire chain of care. This covers prehospital care, emergency room assessment and diagnosis, emergency medical treatment, stroke unit care, ongoing rehabilitation and secondary prevention, and access to related neurosurgical and vascular intervention. A stroke unit is the most important component of a stroke center. A stroke center provides stroke unit services for the population of its own catchment area and serves as a referral center for peripheral hospitals with stroke units in case their patients need services that are not locally available (http://stroke.ahajournals.org/content/44/3/828\#T1).

\section{Background and Significance}

AIS caused by ELVO is the leading cause of adult disability in the world. ${ }^{2}$ Strokes caused by occlusion of the large intracranial vessels, such as the internal carotid artery (ICA), proximal middle cerebral artery (MCA), or basilar artery (BA), have low rates of response to IV tPA, resulting in poor outcomes. ${ }^{3}$ The major revolution in AISI began in 2015 when five randomized trials showed that rapid MT significantly improves outcomes in anterior circulation (ICA, M1) ELVO stroke patients. ${ }^{4-8}$ The degree of benefit is profound, with a number needed to treat as low as 2.5 to have one patient be less disabled. ${ }^{9,10}$ Few if any therapies in medicine can approach that level of benefit. Two additional trials have further confirmed that indeed rapid thrombectomy dramatically improves outcomes, including up to $24 \mathrm{~h}$ from last known normal neurological status. ${ }^{1-14}$

Training guidelines for physicians performing AISI were already proposed by the same working group. ${ }^{1}$ Delivering the benefit of this therapy to a population that is applicable in diverse localities throughout the world as reflected by the breath of international societies sponsoring this guideline requires a concerted effort.
Critical to this is ensuring the proper facility capabilities to deliver this treatment in a safe yet timely fashion.

The goal of this document is to provide recommendations that outline the minimum requirements to provide AISI to as large a population as possible, including those that do not have timely access to a level 1 center, which is capable of treating all vascular diseases of the brain and spine.

\section{Purpose}

This is a document that provides recommendations based on expert opinions and best available evidence in relation to the optimal conditions for the safe practice of AISI.

In order to replicate the dramatic results of the major randomized trials, we must ensure patients throughout the world are treated in a center with the capabilities necessary to handle not just the procedural aspects but also the medical management of the patient prior to, during, and post-thrombectomy.

These general recommendations are not a substitute to existing national and regional guidelines, recommendations, and regulations in the field of AIS. Rather, this describes the minimum organization and workload that, based on expert consensus, is necessary for a hospital to practice AISI.

The best option for the management of AIS is to have patients transferred to and treated in high-volume level 1 centers as demonstrated by scientific evidence. ${ }^{15}$ However, in some situations, specifically due to geographical, traffic, and transportation conditions, the access of patients to such centers in an acceptable timeframe may not be possible. In that case, it would be wise to have a system of care that incorporates level 2 centers, able to provide AISI but not necessarily the full spectrum of neuroendovascular procedures.

\section{Where Is AISI Performed?}

The practice of AISI should ideally take place in healthcare institutions that routinely provide services for all neurological disorders and neurointerventional treatments to patients with all kinds of neurovascular disorders (level 1 centers). Recommendations for these centers have been recently published. ${ }^{16}$ 
However, if a level 1 center is not regionally available, a center treating only ischemic stroke (a level 2 center) can be established under the following conditions:

- There is no level 1 center available within $2 \mathrm{~h}$ of interfacility transport time.

- The level 2 center must care for a reasonable number of AIS treatments a year (at least 100 treatments, including intravenous thrombolysis and AISI).

- The institution must incorporate an acute stroke center or stroke unit with fully trained stroke physicians.

- It is highly recommended that the level 2 center be organized in cooperation with a level 1 center, and should pursue the objective of collaborative work with the level 1 center for neurointervention training, continuous medical education, mortality and morbidity rounds, expert advice by teleconsultations, or, by practice, 24-hour/7-week days coverage, referrals, among others).

\section{Level 2 Center: Standards of Practice}

For those centers established under these conditions, the following standards of practice apply:

\section{Facilities}

Facilities that must be available on site include:

- Stroke unit beds: A sufficient number of stroke unit beds should be available in stroke units to accommodate interventionally treated stroke patients at any time.

- An Intensive care unit.

- A radiology/neuroradiology service, with competence in neuroimaging, and a suitable angiography room (as defined below): High-quality, rapidly available non-invasive imaging is vital to the management of the acute stroke patient. At a minimum, CT scanners should be available on a $24 / 7$ basis to image patients with non-contrast CT and CTA. The availability of CT perfusion and/or magnetic resonance imaging may also assist in patient selection for AISI beyond $6 \mathrm{~h}$ from onset. The necessary technologists and support personnel for this imaging should be available and on site at the time of patient admission. Diagnostic radiologists/neuroradiologists with sufficient training and experience in the interpretation of these imaging studies shall be available on a $24 / 7$ basis. Finally, cerebrovascular ultrasound facilities should be available.

- A team of trained acute stroke neurointerventionists.

- A dedicated "stroke unit"? and a "stroke team"? with fully trained stroke physicians.

- A department of neurosurgery ideally in house or, if that is not possible, in a nearby hospital.

\section{Angiography suite}

A suitable interventional angiographic suite implies the ability to routinely accommodate general anesthesia. Optimally, procedures should be carried out under the image guidance of a biplane digital angiography unit with flat panel CT capabilities and necessary software and hardware in order to perform high-quality cerebral angiography.
As a minimum, each suite should include a single-plane high-resolution digital subtraction angiography unit with road mapping capabilities.

Radiation protection measures in accordance with national regulations should be in place with designated individuals responsible for carrying out the necessary checks and audits.

\section{Treatment availability}

AISI should be offered to every appropriate patient according to international guidelines, not excluding/discriminating against any patient, appropriate at the right time to obtain the best results, with population treatment access equity, in centers providing safe, effective, and efficient treatment.

A suitable level 2 center should be able to provide the services defined in the Definitions section on a 24/7 basis, all year around.

\section{Procedural volume}

The randomized trials demonstrating a clear benefit from thrombectomy were almost exclusively performed in high-volume centers. It has been shown that high-volume centers have a significantly lower mortality, even if the patient has to be transferred from a low-volume center. Rinaldo et al. found that centers performing 35 or more thrombectomy cases per year would classify as "high volume"? and offer the lowest mortality rate for patients. ${ }^{15}$ Similarly, the American College of Cardiology Foundation, the American Heart Association, and the Society for Cardiovascular Angiography and Interventions suggest a minimum of 36 percutaneous coronary interventions for acute myocardial infarction per year per center as a minimum requirement. ${ }^{17}$

We acknowledge that the thresholds listed below are generally low. Multiple regional/national recommendations with higher limits are available and should be observed in regions/countries having already advanced healthcare networks providing services for AIS patients. The current recommendations are international and have to be compatible with the development of this new activity in areas and countries, where there had been previously limited availability. Subsequently, these thresholds should be considered as the minimum caseload providing the lowest limit of safe operation. With the increased implementation of AISI in the world, it may be desirable to revise these thresholds in the future.

On the other hand, we also acknowledge that these thresholds are potentially difficult to reach in newly created level 2 centers and recognize that, during a transitory period, the activity can be below the threshold numbers, as long as it is expected that the volumes would be reached within 12-24 months.

With all the above in mind, the suggested thresholds for annual procedure volume in order to maintain the competence for AIS endovascular treatment are the following:

- Each level 2 center shall perform a minimum number of intracranial thrombectomy procedures for ELVO per year. The global consensus group recommends a minimum of 50 procedures per center per year.

- Including the aforementioned thrombectomy procedures, each level 2 center shall perform a minimum total number of neuroendovascular procedures (diagnostic and interventional) per year according to national requirements. The global consensus group recommends a minimum of 120 per center per year. 
- Each neurointerventionist working in a level 2 center must perform a minimum number of acute intracranial thrombectomy procedures per year, in accordance with national requirements. The global consensus group recommends a minimum of 15 procedures per neurointerventionist per year.

- In addition to the aforementioned thrombectomy procedures, each neurointerventionist in a level 2 center should perform a minimum number of total neuroendovascular procedures per year according to national requirements. The global consensus group recommends a minimum of 50 procedures per neurointerventionist per year.

\section{Operational guidelines/Medical personnel}

\section{Stroke team}

Outstanding stroke care does not exist in a vacuum solely focused on the procedure, but instead is part of a successful multidisciplinary team. The stroke team comprises fully trained stroke physicians (vascular neurologists or neurointensivists), allied professionals, and nurses that are all led by a stroke physician with strong background in the management of neurovascular disease.

\section{Level 2 stroke intervention team}

- The team should have a minimum of three clinicians with training and qualification in AISI. ${ }^{18}$

- The team should organize 24/7/365 acute ELVO stroke coverage (possibly in a rotation system organized with other level 2 centers or a level 1 center).

- It is recommended that stroke neurointerventionists involved in AISI maintain outpatient clinics for follow-up and have admitting privileges either in units/beds dedicated to interventional neuroradiology or in other appropriate inpatient facilities.

- The stroke neurointerventionist, in collaboration with the stroke team, should have shared responsibility for pre- and post-operative patient care with input from the appropriate specialties.

- AISI should ideally be practiced in neurointerventional teams with the possibility to exchange of experience and knowledge. Clinical research should be encouraged. The solitary practice of AISI is strongly discouraged.

\section{Anesthesia team}

There shall be 24/7 in-hospital anesthesia coverage with anesthetists experienced in caring for patients undergoing AISI. At many centers, the use of anesthesia, whether monitored anesthetic care or general anesthesia, is routine during thrombectomy. Even at centers primarily using moderate sedation, patients may deteriorate clinically prior to or during the procedure such that immediate access to general anesthesia is necessary to safely complete the procedure.

\section{Others}

Given the significant amount of assistance that stroke patients need to reintegrate into the community, the center should have access to physical therapy, speech therapy, occupational therapy services, as well as a coordinated plan for assessment of rehabilitation needs.

\section{Individual procedures}

With regard to individual procedures, ideally the following staff roles are present for each case:

- One first operator: a neurointerventionist.

- One assistant: a second scrubbed individual (i.e., a supporting AIS interventionist, physician-in-training [resident or fellow], nurse practitioner, physician assistant, a scrub nurse or a radiographer).

- One radiographer.

- One nurse or nurse assistant.

- Regardless of the type of anesthesia, anesthesiology service must be readily available 24/7.

As a minimum, a neurointerventionist, a radiographer, and appropriately trained nurses must be present.

\section{Quality improvement processes}

Treatment of AIS using AISI techniques is a novel method that involves the consumption of significant human and material resources and carries the risk of severe complications. Accurate documentation of medical and technical details as well as patient outcomes and follow-up results is inevitable to ensure the highest benefit of such complex and demanding procedures.

To secure such documentation and data management, the following are recommended:

- The level 2 stroke center team must include a dedicated individual, preferably a stroke nurse or a stroke fellow, with the responsibility of data recording and database management.

- All technical and clinical data of AISI procedures, patient outcomes, and follow up must be entered into an electronic database either locally or (preferably) nationally or internationally.

- The center shall establish target time metrics for all cases in accordance with the most recent requirements by international standards. Cases that exceed their chosen metrics should trigger an internal process for quality improvement. ${ }^{17}$

- The database should be regularly audited. At a minimum, process metrics such as time from arrival to intravenous tPA, to start of angiography and to recanalization, as well as overall recanalization rates are to be reviewed and compared against reasonable published benchmarks.

- The center provides routine continuing education (suggested minimum of $8 \mathrm{~h}$ per year) related to cerebrovascular disease and stroke for all core members of the center as designated by the medical director.

- All cases of symptomatic intracranial hemorrhage (sICH) shall be reviewed. For the purposes of this document, we broadly define sICH as the presence of new intracranial hemorrhage on post-treatment brain imaging, with clinical deterioration that is potentially attributable to the hemorrhage.

- Standardized care pathways should be implemented with clinical practice guidelines, order sets, and other tools to ensure consistent care delivery and minimize practice variability. This should apply for providers, nursing, and ancillary staff. These pathways should be developed by the multidisciplinary leadership of the center and reflect evidence-based practice. 


\section{Community and Emergency Medical Services Outreach}

Outstanding stroke care starts not in the hospital but in the field. Increasingly, operators will likely promote the selection of most appropriate destination for suspected ELVO patients based on distance to a center from the field. $1^{9}$ Such a mechanism should decrease time to treatment. As such, the level 2 center should interface with local Emergency Medical Services (EMS) in order to coordinate care in the pre-hospital arena.

Specifically, we feel there are some key items in this area:

- Representatives of the center shall work with local and regional EMS officials to ensure they are aware of the system's capabilities, as well as which patients (based on the region's chosen severity scale) are appropriate for direct field triage to the level 2 or 1 centers.

- Additionally, some patients may be distant from the ECSC and present to a level 3 center. The level 2 center should work with these local centers to assist in the identification of suspected or confirmed ELVO patients and facilitate rapid transfer as part of a "hub and spoke"? model of care. However, if a level 1 center is available in similar transfer time, it is preferable that inter-facility transfers are directed to the highest-level facility.

- A mechanism should exist for providing feedback to EMS and referring non-thrombectomy centers to highlight which aspects of care went well and identify areas for improvement. This would be similar to quality assessment work done on patients presenting directly to the ECSC.

\section{REFERENCES}

1. Lavine SD, Cockroft $\mathrm{K}$, Hoh $\mathrm{B}$, et al. Training guidelines for endovascular stroke intervention: an international multi-society consensus document. J Neurointerv Surg. 2016;8:989-91.

2. Leslie-Mazwi T, Chandra RV, Baxter BW, et al. Society of neurointerventional surgery. ELVO: an operational definition. J Neurointerv Surg. 2018;10:507-9.

3. Lima FO, Furie KL, Silva GS, et al. Prognosis of untreated strokes due to anterior circulation proximal intracranial arterial occlusions detected by use of computed tomography angiography. JAMA Neurol. 2014;71:151-7.

4. Saver JL, Goyal M, Bonafe A, et al. Stentretriever thrombectomy after intravenous t-pa vs. T-pa alone in stroke. N Engl J Med. 2015;372:2285-95.
5. Jovin TG, Chamorro A, Cobo E, et al. Thrombectomy within 8 hours after symptom onset in ischemic stroke. N Engl J Med. 2015;372:2296-2306.

6. Goyal M, Demchuk AM, Menon BK, et al. Randomized assessment of rapid endovascular treatment of ischemic stroke. N Engl J Med. 2015;372:1019-30.

7. Campbell BC, Mitchell PJ, Kleinig TJ, et al. Endovascular therapy for ischemic stroke with perfusion-imaging selection. N Engl J Med. 2015;372:1009-18.

8. Berkhemer OA, Fransen PS, Beumer D, et al. A randomized trial of intraarterial treatment for acute ischemic stroke. N Engl J Med. 2015;372:11-20.

9. Goyal M, Menon BK, van Zwam WH, et al. Endovascular thrombectomy after large-vessel ischaemic stroke: a metaanalysis of individual patient data from five randomised trials. Lancet. 2016;387:1723-31.

10. Saver JL, Goyal M, van der Lugt A, et al. Time to treatment with endovascular thrombectomy and outcomes from ischemic stroke: a meta-analysis. JAMA. 2016;316:1279-88.

11. Mocco J, Zaidat OO, von Kummer R, et al. Aspiration thrombectomy after intravenous alteplase versus intravenous alteplasealone. Stroke. 2016;47:2331-8.

12. Bracard S, Ducrocq X, Mas JL, et al. Mechanical thrombectomy after intravenous alteplase versus alteplase alone after stroke (THRACE): a randomised controlled trial. Lancet Neurol. 2016;15:1138-47.

13. Nogueira NG, Jadhav AP, Haussen DC, et al. Thrombectomy 6 to 24 hours after stroke with a mismatch between deficit and infarct. N Eng J Med. 2018;378:11-21.

14. Albers GW, Marks MP, Kemp S, et al. Thrombectomy for stroke at 6 to 16 hours with selection by perfusion imaging. N Eng J Med. 2018;378:708-18.

15. Rinaldo L, Brinjikji W, Rabinstein AA. Transfer to high-volume centres associated with reduced mortality after endovascular treatment of acute stroke. Stroke. 2017;48:1316-21.

16. Jansen O, Szikora I, Brückman H, et al. Standards of practice in interventional neuroradiology. Neuroradiology. 2017;59:541-4.

17. Harold JG, Bass TA, Bashore TM, et al. ACCF/AHA/SCAI 2013 update of the clinical competence statement on coronary artery interventional procedures: a report of the American College of Cardiology Foundation/American Heart Association/American College of Physicians Task Force on Clinical Competence and Training (writing committee to revise the 2007 clinical competence statement on cardiac interventional procedures). Circulation. 2013;128:436-72.

18. McTaggart RA, Ansari SA, Goyal M, et al. Initial hospital management of patients with emergent large vessel occlusion (elvo): report of the standards and guidelines committee of the society of neurointerventional surgery. J Neurointerv Surg. 2017;9:316-23.

19. Zhao H, Coote S, Pesavento L, et al. Large vessel occlusion scales increase delivery to endovascular centres without excessive harm from misclassifications. Stroke. 2017;48:568-73.

\section{Editorial comment}

Mechanical thrombectomy has dramatically improved clinical outcome for patients presenting with acute stroke associated with large vessel occlusion. This was demonstrated in multiple international randomized-controlled trials, including an important Canadian trial. A major challenge in providing state of the art acute stroke treatment to all Canadians is related to the large size of the country and the difficulty for acute stroke patients to reach a comprehensive acute stroke management center in a timely fashion.

This recommendation on the standard of practice in acute ischemic stroke intervention is the consensus of representatives from multiple national and international societies, and is being published in multiple scientific journals. It proposes criteria for acute stroke care and provides possible solutions for centers remote form the comprehensive stroke centers. It represents an important contribution to the management of patients presenting with acute stroke in Canada. Editor-in-Chief, Canadian Journal of Neurological Sciences

Karel Terbrugge

President, Canadian Society of Neuroradiology 